\title{
Using HR-TEM for Geological Environment Investigation: A Case Study of Silver Nanoparticles Associated with Mine Waste in a World Heritage Site
}

\author{
Brittany A. Cymes ${ }^{1}$ and Mark P.S. Krekeler ${ }^{2}$ \\ 1. Department of Geology and Environmental Earth Science, Miami University, Oxford, OH, USA \\ 2. Department of Geology and Environmental Earth Science, Miami University, Hamilton, OH, \\ USA
}

The New Caledonian archipelago, located approximately 2,000 km east of Australia, is home to one of the world's largest ophiolite complexes - uncommon rock units approximating those found in the Earth's mantle. New Caledonia has the $3^{\text {rd }}$ largest nickel reserve in the world and ranks $5^{\text {th }}$ in global production [1]; nickel is mined from enriched clay minerals formed during tropical weathering the ophiolite underwent since emplacement 35 million years ago [2]. New Caledonia is also home to the world's $2^{\text {nd }}$ most extensive coral reef system. The lagoon between the land and reef crest has been designated a UNESCO World Heritage Site. The present work explores silver nanoparticles discovered during a high-resolution transmission electron microscopy (HR-TEM) based assessment of previously characterized (by other techniques) Ni-rich clay minerals associated with mine waste. These nanoparticles are potentially linked to toxic silver bioaccumulation observed in lagoon organisms [3][4]. This investigation demonstrates the novel data HR-TEM can reveal in geological environmental assessments.

The clay samples in this study were collected from freshwater streams directly associated with mine run-off. Specimens were prepared for HR-TEM by embedment with LR White resin using methanol as the dehydrating agent. This resin embedment is used to decrease beam damage while preserving the natural textures of the hydrous clay minerals [5]. The resin blocks were then embedded in CrystalBond ${ }^{\mathrm{TM}}$, sliced into wafers, hand polished thin, and adhered to $3.0 \mathrm{~mm}$ lacey carbon copper grids with cyanoacrylate. The grids were ion milled at a $4^{\circ}$ glancing angle until visible perforation. The samples were analyzed using a JEOL JEM 2100 TEM with a LaB 6 source and equipped with a Gatan Orius SC200D camera (2k x 2k), and a Bruker Quantax 200 STEMXEDS system. All operations were in brightfield mode and at a $200 \mathrm{keV}$ accelerating voltage.

Ten clay samples were analyzed using the above methodology; silver nanoparticles were observed both independent of and in direct association with the clay minerals in two samples. [6]. In both specimens, the silver nanoparticles were dispersed in amorphous silica, spherical to oblate in morphology, and bimodal in size distribution, with evident Ostwald ripening textures (Fig 1). Selected area electron diffraction (SAED) (Fig 2) and energy dispersive X-ray spectroscopy (XEDS) (Fig 3) indicated the nanoparticles were native silver with minor Al and Fe impurities [7]. This is the first time silver - in any form - has been found in New Caledonia. The textural and chemical data indicate that the silver nanoparticles are derived from ore and mine waste (rather than a synthetic source) and their association with amorphous silica is very similar to cases of epithermal gold deposits, indicating a potentially similar origin [8]. This scenario is consistent with the tectonic history of the weathered ophiolite units. The presence of these nanoparticles is of ecological concern because they are known to be toxic to a wide variety of organisms in low concentrations [9]. In New Caledonian lagoons, silver is noted to be accumulating in the renal and pericardial appendages of nautilus and in the digestive glands and kidneys of scallops. There is potential that the discharge of heavy-metal-rich sediment derived from land-based mining 
activities into the adjacent waterways is related to observed metal accumulation in the local ecosystem.

The major analytical implication of this work is that HR-TEM investigation of well-characterized geologic materials can facilitate discovery of additional components not discernable with traditional bulk analytical techniques such as X-ray diffraction and mass spectrometry. In addition, the instrumental resolution allows for tenable interpretation of material nano-textures and bulk chemistry, key for determining contaminant origin. In the case of New Caledonia, the discovery of silver nanoparticles associated with mine runoff can be potentially linked to observed toxic bioaccumulation of silver in the local ecology, demonstrating the need for additional sampling and investigation into this issue. This work is important as it integrates geology and high resolution microscopy to address an ecological disturbance as a result of mine-related activity.

\section{References:}

[1] U.S. Geological Survey, Mineral Commodity Summaries (2016)

[2] B Pelletier, Compend Mar Species N Caled Dossiers Scientifiques Techni 117 (2007) p. 19

[3] P Bustamante et al, Mar Pollut Bull 40 (2000) p. 688

[4] C Levard et al, Environ Sci Technol 46 (2012) p. 6900

[5] MPS Krekeler, S Guggenheim, J Rakovan, Clays Clay Miner 52 (2004) p. 263

[6] B Cymes, M.Sc. Thesis Ball St Uni (2016)

[7] MI Novgorodova, AI Gorshkov, AV Maokhov, Int Geol Rev 23 (1981) p. 485

[8] M Burke, J Rakovan, MPS Krekeler, Ore Geol Rev (2017) p. 708

[9] M Metian et al, Environ Pollut 152 (2008) p. 543

[10] The authors acknowledge Dr. Richard Edelmann and Mr. Matthew Duley of Miami University's Center for Advanced Microscopy and Imaging. This work was partially supported by a graduate student grant awarded to Brittany Cymes during her time at Ball State University.
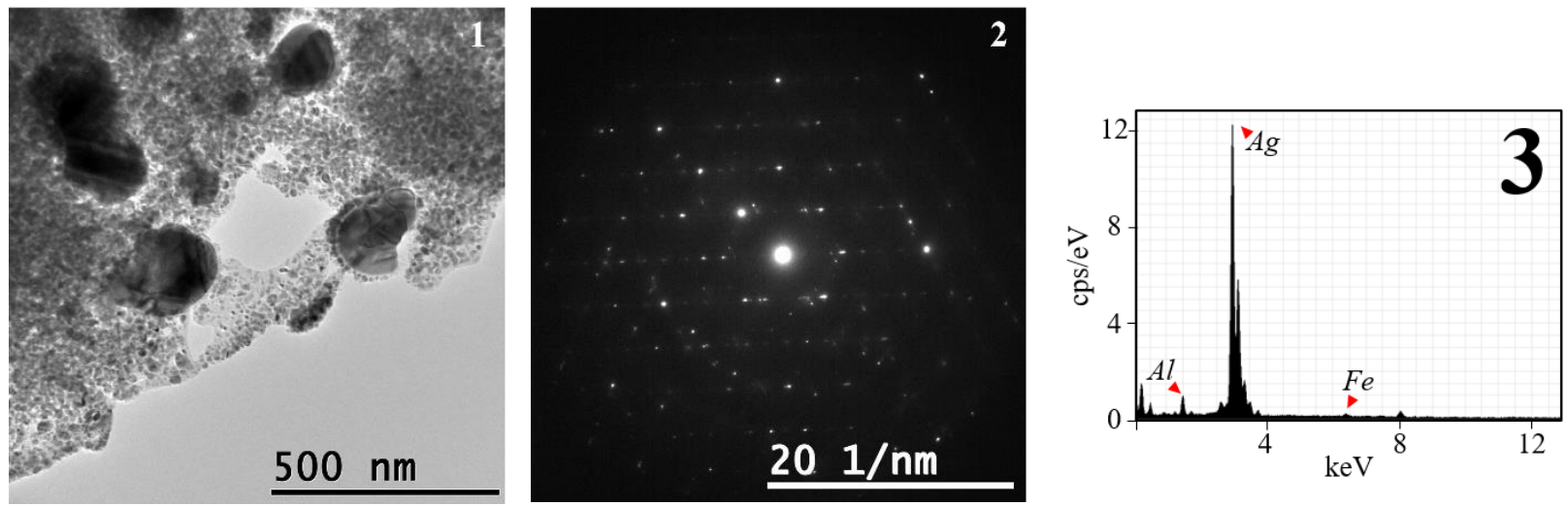

Figure 1. HR-TEM brightfield micrograph of silver nanoparticles.

Figure 2. SAED pattern of a silver nanoparticle; $\mathrm{d}_{(111)}=2.39 \AA, \mathrm{d}_{(200)}=1.98 \AA, \mathrm{d}_{(200)}=1.44 \AA$.

Figure 3. XEDS of a silver nanoparticle showing major $\mathrm{Ag}$ with minor $\mathrm{Al}$ and $\mathrm{Fe}$. 